\title{
Actividades Participadas pelos Pais na Aprendizagem da Química (PAQ)
}

\author{
J O Ã $O \quad \mathrm{PAIVA}^{*} \mathrm{E}$ M A R I A FIL O M E N A G A S P A R**
}

\section{Resumo}

Há uns meses circulou de forma mediática a chamada "greve aos TPCs (Trabalhos Para Casa)». Fosse a inciativa "greve aos maus TPCS» e os autores deste artigo teriam aderido... De facto, o que está mal não são os TPCs mas, porventura, a retardada renovação e modernização científico-pedagógica dessas tarefas para realizar em casa. Uma "greve aos TPCS» pode ser tão descabida como uma "greve às aulas»: mude-se a escola mas não se acabem com as aulas, claro!

TPCs de Química diferentes ter-se-ão de adaptar à progressiva contextualização da Ciência e a alguns enqua- dramentos pedagógicos contemporâneos (não tão novos como isso mas difíceis de penetrar na realidade escolar). A família, como pedra-chave do contexto sociocultural e, por isso, importante para a Ciência, desempenha um papel fundamental.

Nas linhas seguintes apresentamos alguns argumentos para a participação dos Pais na aprendizagem de Ciência e apontamos estratégias para um maior envolvimento destes nas tarefas de casa, tendo em conta as novas formas (contextualizadas) de ver a Química e, consequentemente, de a ensinar e aprender.
Escola, família e comunidade: novas tendências curriculares no ensino

\section{A crucialidade do meio na aprendizagem: 0 desenvolvimento em contexto}

A concepção do aluno como um ser social e cultural, que se desenvolve como ser humano na interacção com outros (contextos, pessoas, objectos e meios mediacionais), que não nasce mas que se constrói, que não assimila mas que se apropria de conceitos a que tem de atribuir significado, desafia-nos a abandonar concepções de escola como um sistema isolado, de professor como es- pecialista numa disciplina, de aquisição de saberes sem funcionalidade e significado social, cultural e de comunicação. Central é o desafio da qualidade desses contextos e dessas interacções sendo, sem qualquer dúvida, um dos marcadores dessa qualidade a interacção que os diferentes contextos estabelecem entre si.

Estes são alguns dos desafios que nos coloca a emergência do paradigma do desenvolvimento em contexto, marcado pela influência do modelo bio-ecológico de Bronfenbrenner (1979; Bronfenbrenner \& Ceci, 1994) e também pela teoria sociocultural de Vygotsky (Gaspar, 2000; Vygotsky, 1978).

Quais as lentes que a teoria desenvolvida por Vygostsky, e apropriada por autores como Werstch, Cole, Rogoff e Valsiner nos propõe para esta leitura que pretendemos responsabilizante de práticas educativas de qualidade? São lentes concêntricas, com círculos crescentes, em que no centro encontramos uma apropriação, que por sua vez ocorre numa interacção que acontece numa zona de desenvolvimento, a que Vygotsky chamou de Zona de Desenvolvimento Próximo (ZDP) (cf. Figura 1).

\footnotetext{
*Departamento de Química da Faculdade de Ciências da Universidade do Porto; email: jpaiva@fc.up.pt

** Faculdade de Psicologia e Ciências da Educação da Universidade de Coimbra; Centro de Psicopedagogia; docente da disciplina de Desenvolvimento Curricular do Mestrado em Química para o Ensino da Faculdade de Ciências da Universidade do Porto; email: ninigaspar@fpce.uc.pt
} 


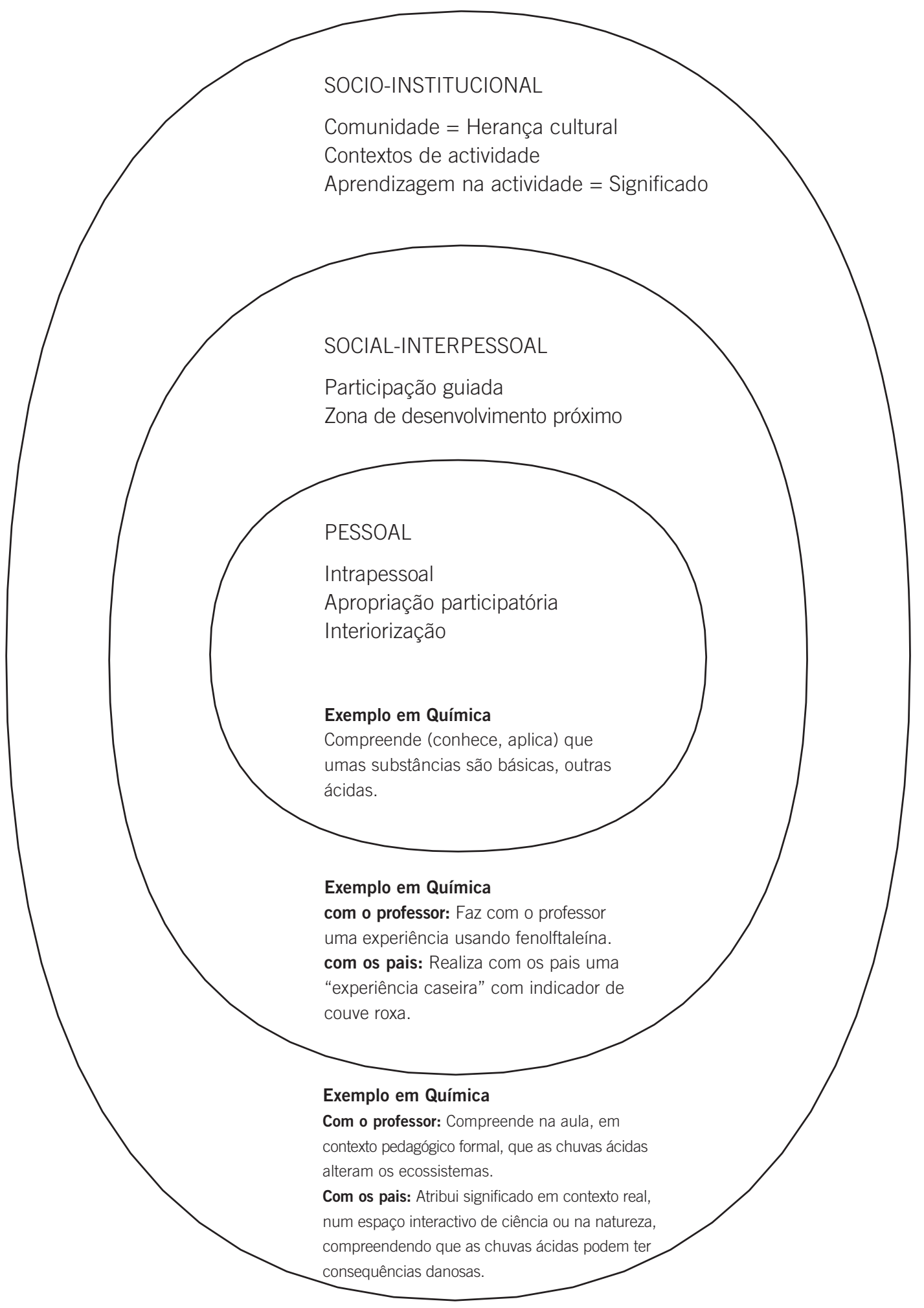

Figura 1 Planos (lentes) dos processos da actividade sociocultural

Este conceito foi desenvolvido a partir do postulado básico da origem social das funções cognitivas superiores, da relação entre o funcionamento interpsicológico e intrapsicológico. É nesta zona que a assistência dos outros permite à criança/aluno internalizar novos tipos de ex- periência. Na sua obra "Mind in Society", Vygotsky define a ZDP como a distância entre o nível de desenvolvimento real da criança, determinado por meio da resolução independente do problema, e o nível de desenvolvimento potencial, determinado através da resolu- ção de problemas sobre a orientação de um adulto ou em colaboração com pares mais capazes de o resolverem (1978). Moll considera este conceito não só como o conceito mais influente da teoria, como também o "conceito conector", no sentido em que integra uma 
grande quantidade de ideias de Vygotsky, nomeadamente: a da actividade cultural e a prática social como fontes do pensamento; a importância da mediação no funcionamento psicológico humano; a centralidade da educação no processo de desenvolvimento; e a inseparabilidade do individual e do social, ao mesmo tempo que encerra uma concepção da relação entre a aprendizagem e o desenvolvimento (cf. Moll, 1990/1996, pp. 4-5). Nesta perspectiva, a "cultura" não é apenas algo com que os indivíduos interagem, a cultura, enquanto acumulação da legitimação histórica da humanidade fora das fronteiras do organismo, é interiorizada como actividade mental, "os seres humanos são cultura interiorizada".

Relativamente ao aspecto da relação entre o ensino (instruction) e o desenvolvimento, o conceito de ZDP e o conceito que lhe está associado de "desempenho assistido" traz implicações profundas para a prática educacional e para as suas relações com o desenvolvimento. A questão é determinar como é que o funcionamento interpsicológico pode ser estruturado para maximizar o crescimento do funcionamento intrapsicológico. A organização do desenvolvimento da criança é concebida como encontrando-se nas mãos de outros mais competentes que a rodeiam, em contextos em que se espera que se desenvolva em determinada direcção, sendo, claro está, os locais formais de ensino os mais salientes a este respeito. O conceito de ZDP, ao conceptualizar que aquilo que a criança faz hoje em colaboração será capaz de fazer amanhã sozinha, através de um processo de "interiorização", encerra a ideia de que a performance existe antes da competência. Há assim um movimento do plano social para o plano psicológico, do "intermental" para o "intramental", da regulação social para a auto-regulação. O desenvolvimento do processo individual de auto-regulação é uma das características do processo de internalização e constitui uma das características dos processos mentais superiores definidas por Vygotsky. Wertsch e Hickmann sugerem que a transição da actividade conjunta para a regulação individual é um processo no qual a criança se torna "consciente" do significado funcional dos comportamentos que realizou sobre a orientação de um adulto, no sentido de perceber como esses comportamentos constituem meios apropriados de atingir um objectivo particular (1987, p.262, citados por Rogoff, 1990, p.204).

A funcionalidade e significado são, assim, outras lentes que nos são propostas pela perspectiva vygotskiana. Como refere Rogoff (1990, p.7), o objectivo do pensamento é agir de forma efectiva, sendo as actividades dirigidas para objectivos, explícitos ou implícitos, definidos socioculturalmente, tal como o são os instrumentos disponíveis para os resolver e as soluções consideradas mais adequadas para o conseguir, ocorrendo, simultaneamente, em situações sociais que providenciam oportunidades de resolução a partir das "transacções sociais". Assim sendo, a assumpção básica é a de que o pensamento e a aprendizagem são esforços funcionais dos indivíduos para resolver problemas específicos com importância na sua cultura. Têm de ser funcionais, ter significado social, cultural e comunicacional.

Temos ainda a lente que nos impulsiona a olhar para os contextos onde essas interacções ocorrem e que as determinam. Apesar de Vygotsky estar já consciente da importância dos contextos nos processos interpsicológicos que ocorrem na ZDP, tendo ele próprio afirmado que o "process of instruction that takes place before school age is essentially different from the process of school instruction" (1956, p.445, citado por Wertsch, 1985, p.74), em termos de investigação concreta não explorou como é que as forças sociais institucionais influenciam o funcionamento mental, ou seja, centrou-se nos processos sociais interpsicológicos e não nos processos sociais institucionais, apesar de também os reconhecer como "sociais". A questão que se coloca é a de como é que o funcionamento interpsicológico encontrado nas ZDP varia em função dos contextos sociais institucionais em que ocorre, ou seja, como é que contextos sociais institucionalmente definidos, como o jogo, a aprendizagem formal, a aprendizagem informal e o trabalho, determinam uma mudança na natureza das interacções e nas ZDPs.

Estes são os três círculos concêntricos das nossas lentes de leitura das relações entre os contextos de actividade e o desenvolvimento/aprendizagem individual (cf. Figura 1): social-institucional; interpsicológico (ZDP); intrapsicológico. Como afirma Leont'ev "(...) if we removed human activity from the system of relationships and social life, it would not exist and would have no structure. With all its varied forms, the human individual's activity is a system in the system of social relations." (1981, p.47, citado por Cole, 1985, p.151; Wertsch, 1985, p.211).

Rogoff desenvolveu as metáforas da "aprendizagem na actividade" (apprenticeship), da "participação guiada" (guided participation) e da "apropriação participatória" (participatory appropriation) para descrever os processos da actividade sociocultural que ocorrem, respectivamente, nos três planos que acabámos de discutir: o social-institucional/da comunidade, o social-interpessoal e o pessoal ${ }^{1}$.

Este paradigma fundamenta, e exige, como tentámos mostrar, um modelo de ensino que vai além da escola, uma perspectiva de aluno que se desenvolve ao aprender, de funções cognitivas que têm de ser apropriadas, ter funcionalidade e significado, e ser auto-reguladas, nos diferentes contextos. Exige, portanto, envolver a família e a comunidade, dar funcionalidade aos conteúdos, contextualizando-os e utilizando-os nos diferentes sistemas, permitindo a sua apropriação de uma forma individualizada e auto-regulada. Como veremos mais à frente, acabámos de enunciar os principais pressupostos que fundamentam a utilização das TIPS (Teachers Involving

10 modelo bio-ecológico de Bronfenbrenner também nos propõe uma conceptualização destas transacções recíprocas entre contextos ou sistemas e o desenvolvimento individual, oferecendo-nos uma outra leitura, complementar, dos conceitos de "ambiente" e de "processo" no desenvolvimento psicológico. 
Parents in Schoolwork) na aprendizagem, nomeadamente na aprendizagem da Química.

\section{O caso particular dos curricula portugueses de Química}

No ensino de Química do sistema português as tendências atrás desenvolvidas estão bem presentes, quer no ensino básico quer no ensino secundário.

Vejamos, a título de exemplo, algumas passagens dos preâmbulos dos textos curriculares actuais, que explicitam a sensibilidade face à envolvência do meio na aprendizagem da Química. Desde logo, no ensino básico, se abrem portas a uma formatação curricular diferente, onde se advinha o esbater do monopólio do espaço escola na aprendizagem: "As 'Orientações Curriculares' que se apresentam estão na sequência do documento em que se definem as Competências Essenciais para as Ciências Físicas e Naturais no Ensino Básico, tomando-o, por isso, como referência. A opção pelo termo orientações curriculares em vez de programas inscreve-se na ideia da flexibilização curricular, tentando que o currículo formal possa dar lugar a decisões curriculares que impliquem práticas de ensino e aprendizagem diferentes" (Programa Básico, 2001).

A (nova) forma como a avaliação é entendida tem uma forte componente do meio envolvente e o convite à intervenção dos Pais: "A educação em Ciência permite, assim, desenvolver e avaliar a competência para compreender a linguagem e a argumentação científicas, de um modo crítico, bem como a apresentação das ideias científicas - por exemplo, através de cartazes ou oralmente, aos colegas, professores ou agentes da comunidade. Interessa não só verificar se os alunos compreendem o que uma ideia é mas também porque é que ela é importante".

No ensino secundário, pela faixa etária dos alunos, naturais rupturas com os progenitores podem marcar um estilo de aprender mais autónomo e desligado da ambiência familiar. Porém, respeitando tal e promovendo a necessária (e fundamental) autonomia, há espaço para a in- teracção com os Pais, na aprendizagem em Ciência.

O conceito de literacia científica é basilar nos actuais programas de Química do Ensino Secundário, como o é, aliás, nos programas do ensino básico. Nas finalidades do programa está claro que a Química tem "de ser encarada como uma via para o crescimento dos alunos e não como o espaço curricular onde se "empacotam" conhecimentos exclusivamente do domínio cognitivo, com pouca ou nenhuma ligação à sociedade". Este crescimento, como sabemos, é sempre psico-bio-social e, bem entendido, só tem a ganhar com a participação efectiva e proporcionada do espaço familiar. Por outro lado, a própria educação escolar em Ciência pode "alimentar cientificamente" a sociedade, pela excelência do canal familiar, no sentido em que "a educação pela Ciência tem como meta a dimensão formativa e cultural do aluno através da Ciência, revalorizando objectivos de formação pessoal e social (educação do consumidor, impacto das actividades humanas no ambiente, rigor $e$ honestidade na ponderação de argumentos, ...)" (Programa 10. ${ }^{\circ}$ ano, 2003).

Pelo exposto parece claro que os novos programas convidam a uma maior integração dos Pais na aprendizagem científica dos filhos, ainda que mais implícita que explicitamente. Porque são, apesar de tudo, realidades relativamente novas, há muito ainda por fazer...

Convém salientar que a polarização nos contextos não significa (ou não deve significar) um desleixo pela estruturação dos conceitos e, claro está, pela clareza e rigor de toda a estrutura conceptual que rege a Ciência e que é absolutamente crucial. Trata-se, porém, no terreno escolar, de acordar para o ensino de uma Ciência, como a Química, que não é, absolutamente, independente do contexto social, afectivo e cultural que vivemos.

Ainda para desfazer eventuais equívocos é bom deixar claro que o envolvimento dos Pais nos TPCs não pode ser entendido como "os Pais a fazerem os trabalhos de casa dos filhos". A este propósito, aliás, é bom ter espírito crítico acutilante em relação a essa autêntica "doença" generalizada de alguns encarregados de educação que protagonizam demais nos trabalhos escolares dos educandos e thes cerceiam a autonomia, não só cognitiva como social e afectiva. Como veremos adiante, os trabalhos de casa terão sempre de ter uma forte componente individual, na perspectiva da auto-regulação cognitiva.

\section{As TIPS como estratégia de envolvimento dos Pais na aprendizagem em Ciência}

\section{0 que são as TIPS?}

TIPS é acrónimo, como foi dito, de Teachers Involving Parents in Schoolwork. Epstein propõe-nos a seguinte tipologia dos seis tipos de parcerias entre a família, escola e comunidade (Epstein et al., 2002):

1. Parentalidade - Apoiar todas as famílias no estabelecimento de ambientes familiares que apoiem as crianças enquanto alunos;

2. Comunicação - Estabelecer formas eficazes de comunicação casa-escola e escola-casa acerca dos programas educacionais e dos progressos das crianças;

3. Voluntariado - Recrutar e organizar a ajuda e suporte dos pais;

4. Aprendizagem em casa - Disponibilizar informação e ideias às famílias sobre a forma de ajudarem os alunos com os trabalhos de casa e outras actividades relacionadas com o currículo, decisões e planificação;

5. Tomada de decisão - Envolver os pais nas decisões da escola, desenvolvendo líderes e representantes dos pais;

\section{Colaboração com a comunidade -} Identificar e integrar recursos e serviços da comunidade para fortalecer os programas da escola, as práticas familiares e a aprendizagem e desenvolvimento dos alunos.

Nesta tipologia o tipo 4 "aprendizagem em casa" pode envolver as seguintes práticas:

- Informações para as famílias sobre as aptidões que os alunos precisam em 
todas as disciplinas em cada nível escolar;

- Informações relativas às políticas da escola sobre os trabalhos de casa e de como fazer a supervisão e discutir o trabalho escolar em casa;

- Informações de como apoiar os alunos para melhorarem aptidões em vários conteúdos e avaliações escolares;

- Planificação regular (semanal ou quinzenal) de trabalho de casa que implique que os alunos têm de discutir e interagir com os pais sobre o que estão a aprender na escola (TIPS);

- Calendários com actividades para os pais e alunos fazerem em casa ou na comunidade;

- Actividades de matemática, ciência e leitura em família na escola;

- Pacotes de actividades para as férias de verão;

- Participação das famílias na definição dos objectivos para os alunos anualmente e na orientação para a universidade ou trabalho.

Neste modelo as TIPS têm como principal objectivo envolver os pais, em casa, no trabalho escolar. O pressuposto que as fundamenta é de que existe trabalho de casa (TPC) que o aluno deve fazer sozinho, em casa, e cujos objectivos são praticar o que foi dado na escola, estudar e desenvolver a auto-regulação. Este trabalho deve ser feito individualmente pelo aluno, sem o envolvimento da família. Outro tipo de actividades a desenvolver em casa, diferente, é aquele que visa desenvolver a parceria entre a escola, a família e o aluno - as TIPS. Este trabalho de casa interactivo, regular, dá aos alunos a responsabilidade de discutirem coisas importantes que aprenderam e ajuda as famílias a estarem conscientes do conteúdo das actividades curriculares dos seus filhos na escola.

Sendo o objectivo das TIPS o desenvolvimento de parcerias, levando o aluno a partilhar em casa o que aprendeu em contexto escolar, ultrapassam muitos dos problemas colocados pelos TPC (trabalhos para casa) ao:
- potenciar o envolvimento de todas as famílias e não apenas daquelas que sabem como discutir matemática, ciências e outros conteúdos com os seus filhos;

- dar a responsabilidade dos trabalhos de casa (TPC) aos alunos individualmente, distinguindo-os claramente das TIPS, não pedindo aos pais que ensinem conteúdos para os quais não estão preparados ou que se sintam culpados por não o poderem ou conseguirem fazer;

- criar condições para que os alunos partilhem o seu trabalho, progressos e ideias com as suas famílias e que tenham prazer nisso;

- potenciar que as famílias comentem e solicitem aos professores informações numa secção das TIPS destinada à comunicação casa escola.

Neste contexto aumentam as probabilidades de os pais reconhecerem o esforço que os professores estão a fazer para os manter informados e envolvidos - a escola é colocada nas prioridades da família e permite que os alunos percebam que o que aprendem na escola é importante para a família. Um desafio importante que se coloca às escolas é o de coordenarem o trabalho de casa ligado à família proposto pelos diferentes professores.

As TIPS obrigam-nos assim, e como afirma Epstein (Epstein et al., 2002) a duas grandes redefinições:

- De "trabalhos de casa" para significar não apenas o trabalho que o aluno deve fazer sozinho, em casa, mas também actividades interactivas partilhadas com as famílias ou com as comunidades, ligando o trabalho na escola a situações reais;

- De "ajuda em casa" ou "ajuda dos pais" para significar encorajar, ouvir, responder, premiar, guiar, supervisionar e discutir - e não "ensinar" os conteúdos escolares. Essa não pode ser responsabilidade dos pais

\section{Um exemplo em Ciência}

Os exemplos já disponíveis de TIPS são imensos, concretamente em língua inglesa e mais especificamente no site de referência do grupo de trabalho da Universidade de Johns Hopkins (TIPS, 2005).

Neste momento, depois de cedidas as respectivas autorizações, estamos a traduzir uma selecção de TIPS para o portal de Ciência e Cultura Científica "Mocho" (2002), em www.mocho.pt.

A título de exemplo, e para que se fique com uma ideia mais concreta do que falamos, isolamos na Figura 2 alguns trechos de uma TIPS a disponibilizar naquele portal, relativa ao estudo do calor e energia, para alunos do terceiro ciclo do Ensino Básico.

\section{PAQ: um caso de química}

Quisemos "portuguesar" e especificar para a Química as TIPS, usando o acrónimo PAQ - Pais na Aprendizagem da Química. No número seguinte deste Boletim, apresenta-se uma PAQ concreta, no formato encarte habitual associado a esta revista, com tarefas de caris prático, sobre indicadores caseiros. Trata-se, usando terminologia deste artigo, de uma TIPS em Química.

Notar no exemplo adiante a organização da actividade e, concretamente, a forma como esta actividade estimula as relações entre família e comunidade, dá funcionalidade aos conteúdos aprendidos, e contextualiza aprendizagens, permitindo a apropriação individual e auto-regulada.

É bom salientar, aliás, que, na sequência dos programas curriculares que existem, se pretende progressivamente evitar o carácter "receituário" das actividades laboratoriais/experimentais em Química. Não é o caso, contudo, de abandonar completamente o carácter prescritivo de algumas iniciativas. Com efeito, para conferir segurança a Pais e alunos, embora estimulando sempre espaços de auto-construção de roteiros e delineamentos de experiências em dinâmicas de projectos, um certo dirigismo nas PAQs pode conferir seguranças aos intervenientes (pais e alunos) e, pelo menos numa primeira fase, tornar estas iniciativas mais populares, funcionais e democráticas. 


\section{Quente-quente}

Caro pai/mãe ou encarregado de educação de

Em Ciências Físico-Químicas, estamos a estudar a energia e o movimento das moléculas. Esperamos que gostem desta actividade que vamos fazer em conjunto. Esta tarefa deverá ser terminada em

OBJECTIVO - Compreender como a energia provoca o movimento das moléculas.

MATERIAIS: garrafa de plástico vazia com tampa, taça grande (sem ser de vidro), água, suportes de frascos, 1-2 couvettes de gelo, três copos, um corante alimentar escuro, relógio com ponteiro de segundos.

\section{SEGURANÇA: ESTA ACTIVIDADE ENVOLVE FOGO! PROCEDIMENTO}

Pedir a um familiar para ajudar como "oficial de segurança" nestas investigações. Explicar todos os passos à medida que se vão executando. Quem está a trabalhar contigo?

1. Coloca uma garrafa vazia de plástico numa taça, dentro do lava-louça.

2. Ferve água numa chaleira. Verte a água lentamente e com cuidado na garrafa vazia. Passado um minuto, usa o suporte de frascos para segurar a garrafa e deita a água no lava-louça. Enrosca a tampa da garrafa RAPIDAMENTE. O que acontece aos lados da garrafa? Regista as tuas observações.

3. Agora deita os cubos de gelo na taça à volta da garrafa. Podes até cobrir ou esfregar com gelo os lados da taça. 0 que acontece aos lados da garrafa agora? Regista as tuas observações.

4. Desenha a garrafa depois de teres deitado a água quente fora e colocado dentro os cubos de gelo. Legenda os teus desenhos para observar como as moléculas que constituem o ar, na garrafa, se comportam em cada caso.

\section{CONCLUSÕES}

1. Qual é a tua conclusão sobre o efeito das diferenças de temperatura no movimento das moléculas de ar na garrafa?

2. Verificarias estas alterações se a garrafa usada fosse de vidro?

Porquê? (Fazer essa experiência se possível)

COMUNICAÇÃO ESCOLA-CASA

Caro pai/mãe,

Por favor deixe as suas reacções ao trabalho do/da seu/sua filho/filha nesta actividade. Escreva SIM ou NÃO em cada uma das frases seguintes:

1. O/A meu/minha filho/filha compreendeu o trabalho de casa e foi capaz de o discutir.

2. __ O/A meu/minha filho/filha e eu gostámos desta actividade.

3. Este trabalho ajudou-me a perceber o que o/a meu/minha filho/filha está a aprender em Ciências.

Outros comentários:

Assinatura:

Figura 2 Alguns excertos de uma TIPS disponibilizada em www.mocho.pt

\section{Notas finais}

Pretendemos, a breve trecho, iniciar as primeiras experiências em terreno escolar com monitorização e avaliação sistemática do impacto que representam as PAQ na aprendizagem dos alunos (e dos Pais!). Uma tese de mestrado está já a empreender esse caminho e outros trabalhos congéneres estão na calha.

Pela natureza sintética deste artigo não pudemos explorar exaustivamente todas as rubricas. O planeamento das actividades que envolvem os Pais e a respectiva avaliação, por exemplo, não foram referidas explicitamente mas são de importância vital.

Esta reflexão impele-nos para uma utilização mais generalizada das actividades $P A Q$, esperando nós que se torne incentivo a uma aprendizagem da Química mais motivante, participada e eficaz. As linhas que se escreveram correspondem 
a uma interacção profícua entre áreas das Ciências de Educação e da Ciência Química. É tempo de atenuar os extremismos e procurar sinergias eficazes no ensino da Química; colocar em diálogo áreas que muitas vezes estão de costas voltadas...

\section{Bibliografia}

Bronfenbrenner, U. (1979). The Ecology of Human Development. Cambridge MA: Harvard University Press.

Bronfenbrenner, U, \& Ceci, S. (1994). Nature-Nurture Reconceptualized in Developmental Perspective: A Bioecological Model. Psychological Review, 101(4), 568-586.

Cole, M. (1985). The Zone of Proximal Development: Where Culture and Cognition Create Each Other. In J. Wertsch (Ed.), Culture, Communication, and Cognition: Vygotskian Perspectives (pp.146-161). Cambridge: Cambridge University Press.
Costa, L., Fiolhais, C., \& Paiva, J.C.; "MOCHO": Um Portal de Ciência e Cultura Científica; IE-2002 - Congresso Iberoamericano de Informática Educativa, Vigo, 117-224; 2002. Disponível em http://www.jcpaiva.net/?d= curiculum/9/942.

Epstein, J. et al. (2002). School, Family, and Community Partnerships: Your Handbook for Action, Second Edition. Thousand Oaks: Corwin Press.

Epstein, J. L., Van Voorhis, F. L., \& Batza, C. (2001). Teachers Involve Parents in Schoolwork (TIPS) Science Prototype Activities for Grade 3. Baltimore, MD: Center on School, Family, and Community Partnerships, Johns Hopkins University.

Gaspar, M. (2000). Um Diálogo sobre Vygotsky e a Educação. Diálogos em Educação, n. ${ }^{\circ}$, Núcleo de Análise e Intervenção Educacional, Faculdade de Psicologia e de Ciências da Educação da Universidade de Coimbra.

Moll, L. (Ed.) (1996). Vygotsky e a Educação: Implicações Pedagógicas da Psicologia Sócio-histórica (Trad. F. Tesseler). Porto Alegre: Artes Médicas. (Original publicado em 1990).
Programa Básico (2001). CIÊNCIAS FísICAS E NATURAIS, ORIENTAÇÕES CURRICULARES - 3 . $^{\circ}$ CICLO DO ENSINO BÁSICO, [online] [consult 1401-2005]. Disponível em http://www.deb.minedu.pt/curriculo/Reorganizacao_Curricular/re orgcurricular_orientcurriculares.asp.

Programa de Química, 10. ${ }^{\circ}$ ano (2003). Programa de Física e Química A 10. ${ }^{\circ}$ ano, [online] [consult 14-01-2005]. Disponível em http://www.des.min-edu.pt/download/ prog_hom/fisica_quimica_a_10_homol_nova _ver.pdf.

Rogoff, B. (1990). Apprenticeship in Thinking: Cognitive Development in Social Context. New York: Oxford University Press.

TIPS (2005) - Teachers Involve Parents in Schoolwork. Disponível em http://spearfish. k12.sd.us/west/Specials/Penny/Teacher\%20I nvolve/ScienceAct.htm, consultado em 18 de Janeiro de 2005.

Vygotsky, L. (1978). Mind in Society: The Development of Higher Psychological Processes. Cambridge, MA: Harvard University Press.

Wertsch, J. (1985). Vygotsky and the Social Formation of Mind. Cambridge, MA: Harvard University Press.

\section{Eliminar o enxofre}

Investigadores holandeses descobriram uma explicação para o facto da actividade dos catalisadores usados na produção de combustíveis limpos diminuir gradualmente. Os seus estudos demonstram que a causa consiste na perda de átomos de enxofre por parte do catalisador, o que pode levar a uma solução para o problema.

Bas Vogelaar e Jacob Moulijn, da Universidade de Tecnologia de Delft trabaIham com catalisadores de hidrogenoprocessamento que removem compostos de enxofre de combustíveis. Caso estes compostos não sejam removidos, a sua combustão levaria à libertação de óxidos de enxofre poluentes. No entanto, estes catalisadores são irreversivelmente desactivados num período de dois anos. A única solução consiste na sua substituição, que é uma operação cara e morosa.

Os catalisadores típicos são constituídos por um suporte de óxido de alumínio sobre o qual é depositado molibdénio, níquel e cobalto. Durante o refinamento, estes metais formam uma camada cataliticamente activa com o enxofre do óleo.

Vogelaar explica que os catalisadores convertem os compostos sulfurosos de duas formas: o átomo de enxofre é removido directamente do contaminante, ou a remoção é obtida através de um processo de hidrogenação. Pela teoria convencional da catálise, um átomo de enxofre deveria ser primeiro removido da fase activa, de forma a deixar uma posição vaga que fosse ocupada por um átomo de enxofre proveniente do contaminante. No entanto, o trabalho de Vo- gelaar demonstra que o segundo mecanismo, a hidrogenação, pode ocorrer em átomos de enxofre periféricos, e não nas posições vazias. Assim, o modelo proposto pelos investigadores sugere que a perda de átomos de enxofre da fase activa desempenha um papel importante na desactivação do catalisador.

Nos processos industriais, os combustíveis tratados formam frequentemente uma mistura muito complexa, que pode por si só afectar o desempenho dos catalisadores, sendo prematuro extrapolar os resultados desta pesquisa para operações reais. No entanto, Vogelaar acredita que este trabalho pode conduzir a um melhor conhecimento sobre a forma como este tipo de catalisadores actuam. (adaptado de webzine Reactive Reports (2005) 44)

Paulo Brito 


\section{Encontro Nacional da Divisão de Ensino e Divulgação da Química da SPQ (4. $\left.{ }^{\circ} D E D Q\right)$}

27-28 de Outubro de 2005 Parque das Nações - Lisboa (FIL e Pavilhão do Conhecimento)

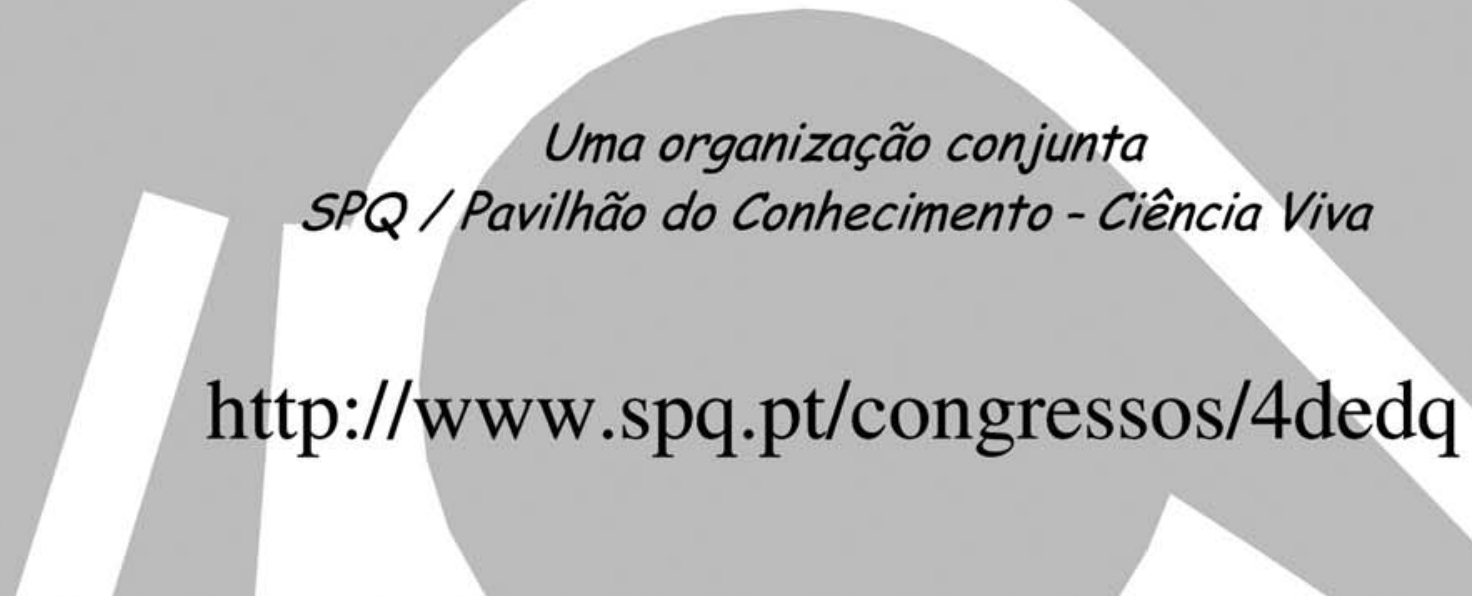

Comissão Organizadora António Costa (Pavilhão do Conhecimento - Ciência Viva) • Eurico Cabrita (SPQ, Universidade Nova de Lisboa) - Paulo Ribeiro Claro (SPQ, Universidade de Aveiro) • Pedro Tavares (SPQ, Universidade Nova de Lisboa)

Programa Provisório • 4 Conferências Plenárias (em confirmação) • 6 Sessões Temáticas Perspectivas CTS do Ensino - Segurança em Laboratórios de Química • Divulgação da Química • Política de Educação e Formação • Ensino Não Formal da Química - Novos Temas Científicos nos Programas do Ensino Secundário - 3 Oficinas ("Workshops") Tecnologias de Informação e Comunicação • Uma visita ao Pavilhão do Conhecimento - Trabalhos Práticos de Química no Ensino Básico - 2 Sessões de Comunicações em Painel - Curso Satélite Trabalhos Práticos do Programa do $12^{\circ}$ Ano (29 de Outubro)

Inscrições Sócio efectivo - $35 € \cdot$ Sócio Estudante $-25 € \bullet$ Não-sócio - $100 €$ 